\title{
Implementation of the Obstructive Sleep Apnea (OSA) Treatments by Mandibular Advancement Appliances
}

\section{Michel Amoric}

Association for the Promotion of Liberal Odontology, 60 rue des écoles 75005 Paris, France

*Corresponding author: Michel Amoric, Association for the Promotion of Liberal Odontology, 60 rue des écoles 75005 Paris, France, Tel: 0633316323 ; Email: michel.amoric@wanadoo.fr

Received date: June 14, 2017; Accepted date: June 19, 2017; Published date: June 26, 2017

Copyright: (C) 2017 Amoric M. This is an open access article distributed under the terms of the Creative Commons Attribution License, which permits unrestricted use, distribution, and reproduction in any medium, provided the original author and source are credited.

\begin{abstract}
The herbst mandibular advancement orthosis on thermoformed gutters is a recognized device for its effectiveness in reducing the apnea-hypopnea index. But its effect may be undermined by poor attendance on the part of the patient. This article poses this problem between the expected effects and those obtained by the healthcare team. It describes some practical solutions to solve them.
\end{abstract}

Keywords: Orthosis; Mandibular advancement; Cooperation; Herbst; Thermoformed gutters; Obstructive sleep apnea

\section{Introduction}

Obstructive sleep apnea-hypopnea syndrome (OSAHS) is a frequent condition in the middle-aged subject. It is characterized by repeated collapse of the upper airways during sleep. It materializes as a nasobuccal flow stop of more than 10 seconds several times per hour. The diagnosis is based on the comparison of clinical signs with a polygraphic record. Professor Guilleminault considers the frequency of five obstructive apneas per hour as pathologic [1]. Hypopnea would be defined as a reduction of more than $50 \%$ of the flow associated with a denaturation of more than $4 \%$.

It is recognized that prior to any treatment, a program to reduce overweight and suppress alcohol, hypnotics or sedatives should be included. In the first instance, prosthetic orthosis are considered to be a therapeutic of choice in mild to moderate apnoea-hypopnea cases (indexes between 15 and 30) without excessive somnolence or severe cardiovascular comorbidity. The expected benefit is a $50 \%$ reduction in the index after regular wearing of the device.

In the second intention they may be indicated when a patient refrains treatment with continuous positive airway pressure.

\section{The Mandibular Advancement Device}

The first non-monobloc mandibular advancement device was described in 1904 by Dr. E. HERBST as part of orthodontic care. After several decades of neglect, the apparatus was taken up, but this time fixed on thermoplastic gutters [2]. We will take this particular device as an example especially since it is the most studied and most widely distributed in the world.

In order to avoid the vagaries of the weld, the pivots were pierced by a rectangular tube of 0.036 size by 0.072 niches intended to receive reinforcing threads. The screw ends with a punch ensuring its holding in the pivot while allowing the unscrewing (Figure 1).

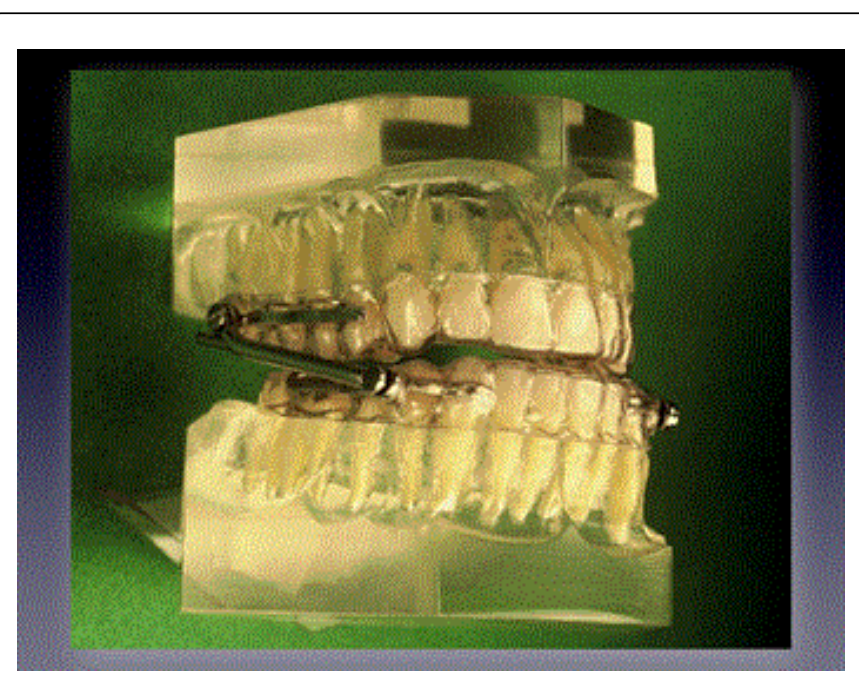

Figure 1: Endobuccal orthosis Herbst manufacturing protocol of Dr. Amoric.

If the pivots are directly bonded to the resin on the gutters, peeling may occur as shown in this picture (Figure 2). To avoid this harmful drawback for good collaboration, we use the following over moulding technique: All inserts (reinforcement, pivots, hooks) are included between two thermoplastic sheets. The first sheet plated on the model is $0.5 \mathrm{~mm}$ thick, the second one $1.5 \mathrm{~mm}$ thick [3] (Figure 3). With this production protocol, the cooperation and the port of the apparatus are considerably improved. The titration (activation of the amplitude of the advancement) is done by reducing the length of the tube part or by adding pieces of tubes crimped on the axis. This allows a progressive activation recommended for eliminating pain in the temporomandibular joint.

Many authors have been interested in the amplitude and frequency of activation in order to achieve an optimum effect of the orthoses without departing from obtaining maximum comfort for the patient. Abrupt or too high amplitude propulsion can lead to genes and pain causing the patients to abandon treatment. Beginning a treatment with 
a low setting represents the best solution to give, this indispensable comfort. At the beginning, the titration can be reduced to 3 or $4 \mathrm{~mm}$. At the end of activation, it can be between 70 and $75 \%$ of the maximum propulsion, i.e. approximately 5 to $8 \mathrm{~mm}$, or more if the apnea index is high.

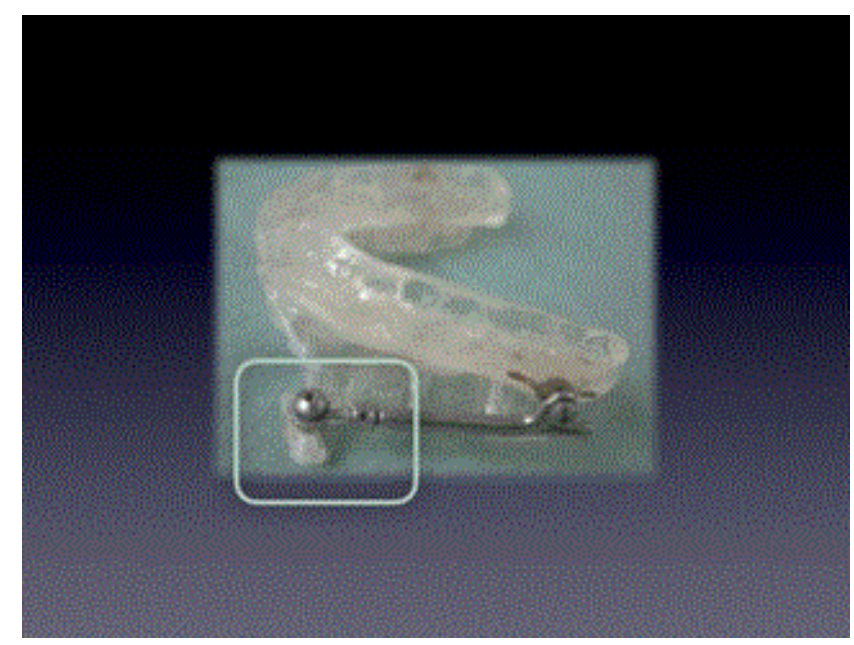

Figure 2: Detachment of a pivot of a Herbst connecting rod attached to the resin to the resin on the thermoformed gutter.

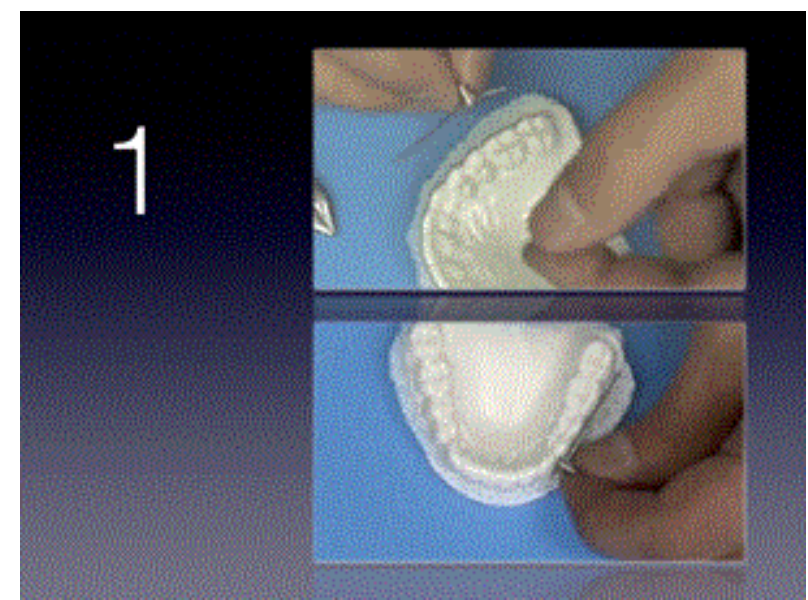

Figure 3: The reinforcing threads and the pivots are glued to a first gutter before being covered by a second plate.

If the gauge is too small, the maximum amplitude may be less than 8 $\mathrm{mm}$. An activation of $2 \mathrm{~mm}$ per month represents the usual incremental rhythm. Some clinicians help feel about snoring or wellbeing. Others rely on oximetry, on the stimulation of the phrenic nerve [4].

In summary, a progressive mandibular advance $(1 \mathrm{~mm}$ by $1 \mathrm{~mm})$, is recommended to improve comfort. It is also found that in order to obtain maximum comfort; the orthosis in adults must be mounted with a minimum height to prevent the tilting of the peri-hyoid and lingual tissues backwards. Beyond $15 \mathrm{~mm}$ of opening between the incisors, the upper respiratory tract collapses. Like all orthotics in thermoformed polymer, mechanical discolorations and alterations can occur over time.

\section{Expected Impact of Advancement Orthosis}

The mandibular advancement has the effect of increasing the velopharyngeal, oropharyngeal and hypopharyngeal [5] caliber, improving the permeability during sleep. The myoelectric activity of the genio-glosses, masticators, external pterygoids and palatoglossus, increases signing a normalization of their tone [6]. The hyoid bone advancing, the tongue is maintained anteriorly. This avoids the pharyngeal collapse.

The first description of apnea treatment by mandibular propulsion dates from the years 1982-1985 [7]. The the first bibliographic synthesis that will be followed by the search engines Medline, Embase, Cinahl, and Cochrane [8]. The latter identified 1475 references, of which 116 are comparative studies. Of those, only 14 were the randomized evidence, because, despite their number, few articles responded to the high level of evidence. As an example, the Cochrane Library [9], oral appliances for obstructive sleep apnea study, this included only 11 randomized cross-over trials and 6 parallel groups of 846 patients. The average duration was only: 2 weeks to 1 year, which is well below acceptable research. And only one study out of the 17 satisfied the double-blind examination. (Quality of the Jadad score less than or equal to 3 , therefore insufficient).

Nevertheless, comparative studies between the effects of mandibular advancement orthoses, placebos, PPC ventilation therapy and surgery have shown that endobuccal orthotics have a sufficiently significant effect on the reduction of the apnea/hypopnea index, The respiratory index of perturbation, the reduction of snoring, are constant advantages of intraoral orthoses to be recognized as a therapeutic to be taken into account in the treatments of SAHOS $[9,10]$. But these devices are less effective in improving daytime sleepiness. Moreover, compliance cannot be validated as for CSF, as the duration of use of the orthosis is difficult to evaluate due to the absence of objective measurements. The degree of compliance and the causes of stopping wearing are largely related to perceived side effects. Compared to placebo intraoral devices, the ability of oral appliances to reduce the apnea/hypopnea index to less than 10 was positively assessed at $54 \%$, when placebos were perceived as $14 \%$ Test sample. Ahrens searched throughout the literature, the effect of inactive devices [11]. He concluded that the majority of studies yield improved subjective results. Specialized research shows the value of the advancement orthosis on diaphragm pressure, on the denaturation of oxyhemoglobin, on microvascular endothelial activity. The mandibular prosthetic orthosis can therefore be proposed either in the case of a rejection of the CPAP or in the first intention, provided that the disorder is associated with severe cardiovascular comorbidity (refractory arterial hypertension, recurrent atrial fibrillation, severe left ventricular insufficiency or Poorly controlled coronary disease, history of stroke).

Itzhaki showed the impact of orthotics on saturation of oxyhemoglobin by recording the level of tiobarbituric acid and malondialdehyde [12]. A mandibular orthesis increases on average the pharyngeal diameter from 3.7 to $4.1 \mathrm{~mm}$ for mandibular propulsion of $7 \mathrm{~mm}[6,13]$. Recently, a Japanese team [14] has just mounted using a fluid mechanics calculation that mandibular advancement allowed a $20 \%$ increase in air velocity and volume. 
Citation: Amoric M (2017) Implementation of the Obstructive Sleep Apnea (OSA) Treatments by Mandibular Advancement Appliances. J Gen Pract (Los Angel) 5: 312. doi:10.4172/2329-9126.1000312

Page 3 of 4

\section{Effects Obtained From Advancement Orthosis}

Depending on the type of survey, $33 \%$ to $50 \%$ of patients give up their orthoses after five years [15]. The attention and competence of practitioners remain the means to improve these disappointing figures.

Knowledge of recurring grievances brings valuable elements to improve comfort and, consequently, patient adherence to their treatment (Figure 4).

These claims concern, in descending order:

- the hypersalonal,

- dry mouth,

- dental or joint pain,

- poor performance of the appliance,

- a change in occlusal perception,

- an amplification of bruxism.

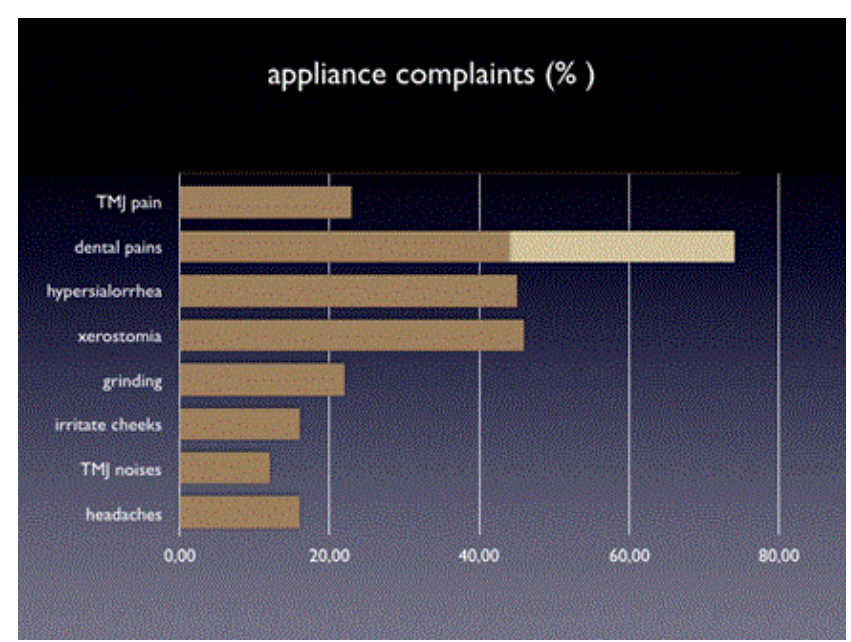

Figure 4: Histograms of the prevalences related to the annoyances perceived by the patients carrying mandibular advances as part of the symptomatic treatment of obstructive sleep apnea.

In addition, the discouragement inherent in the persistence of the symptoms felt, such as snoring. Abandonment is rarely brutal. It occurs, most often, after a progressive loss of confidence. To reduce these drop-outs, authors propose to use relaxation or sophrology. Others suggest using psychological tests to identify potentially resistant patients such as:

- the health perception test (Nottingham profile),

- the mental assessment test (depression test: HADS)

Appropriately, these tests can isolate patients who are unaware of their condition or who are less likely to participate in their treatments.

By this means practitioners can either direct these patients to another type of treatment or defer it.

As a result of a thorough fibroscopic examination, the ENT specialist must also decide on the predisposition of the peripharyngeal tissues to be modified in the direction of an increase under the effect of mandibular propulsion.

Similarly, a defective oral condition represents a reason for exclusion.
For [16] more than 50\% of patients eligible for mandibular advancement gutters would not have an oral condition consistent with advancement orthesis wear.

It is considered risky to propose gutters of advancement to patients with [17-21]:

- periodontal disease,

- dislocations, arthritis, ankylosis of the temporomandibular joints,

- absence of dental organs,

- particular malocclusions $(\mathrm{Cl}$, hyperdivergent or severe hypodivergent, CI ...)

Despite all these precautions, undesirable dental displacements inherent in mandibular propulsion may occur and impede the patient.

According to the authors, $44.3 \%$ to $85.7 \%$ of the cases, can present these displacements. After 7.3 years of wearing a mandibular advancement orthosis [20] finds for $1 / 3$ of the cases:

- an average reduction of $2.8 \mathrm{~mm}$, on average, of the incisive covering,

- an advancement of the lower incisors (from 0.2 to $3 \mathrm{~mm}$ )

- a recoil of the upper incisors (from 0.2 to $2 \mathrm{~mm}$ ) ...

- A flip-flop of the occlusion plane,

- an increase in the height of the upper stage (to $0.8 \mathrm{~mm}$ )

- the flattening of the Spee curve in the premolar area; From mandibular canines to second molars.

These inadvertent movements are only beneficial for Angle II occlusion patients. For others, in normoclusion, classes II 2 or class III this can pose a problem more or less annoying (Figure 5).

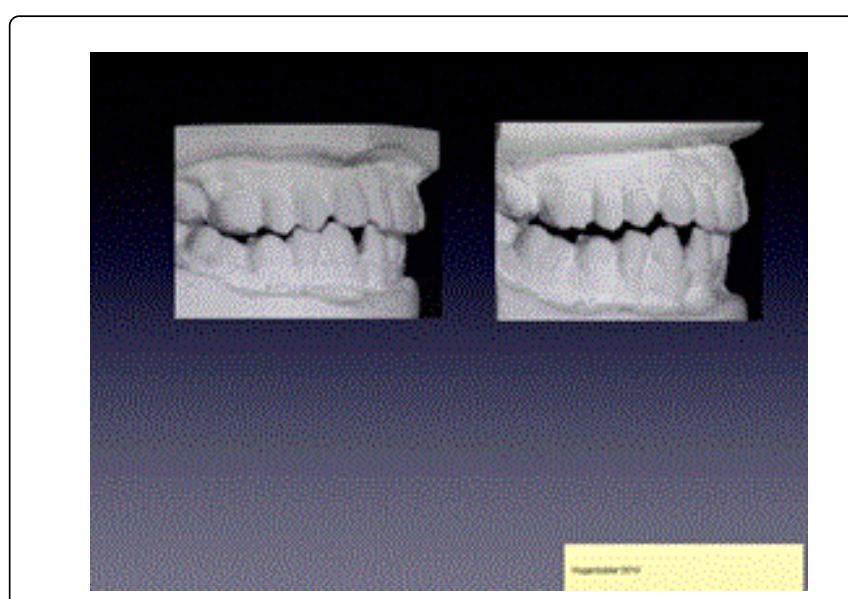

Figure 5: Molds of a case undergo loss of posterior meshing, after wearing a mandibular advancement orthosis.

Of 65 patients treated for three years or more [22] found that $51 \%$ had these side effects. $40 \%$ reported occlusal disturbances. The retrospective study of [23], of 192 subjects, described a change in position of incisors, wear, a significant reduction in vertical $(-0.4 \mathrm{~mm})$ and horizontal Overlaps $(-0.5 \mathrm{~mm})$. Similarly, [17] observed, unpredictable occlusal changes. [20] deepened the study of these dental displacements. After 5 years she noticed that only $14.3 \%$ of the 71 patients had no change in occlusion. $41.4 \%$ of these changes were favorable and $44.3 \%$ were unfavourable. 
It was evaluated that in the long term the wearing of the orthoses had consequences on the overlap and the incisal overhang (respectively of $1.0( \pm 1.5)$ millimeter and $1.7( \pm 1.6)$ millimeter $)$. A palatoversion of the upper incisors is $\left( \pm 2.0^{\circ}( \pm 2.8)\right)$ and a proversion is $\left(3.7^{\circ}( \pm 5.4)\right)$ of the lower incisors [21]. Facial height increased significantly, $0.8( \pm 1.5)$ millimeter and $6^{\text {th }}$ April $2010( \pm 1.4) \mathrm{mm}$, respectively [24].

\section{Conclusions}

The results of the innumerable clinical studies available to us show a frequency of SAHOS in the male population around 1 to $6 \%$ with a lower prevalence in women [25]. Prosthetic orthoses have a good therapeutic choice in the treatment of mild to moderate SAHOS or in the event of rejection of continuous positive airway pressure therapy. But an identical dropout rate affects patients with advancement orthoses. We have shown here that to remedy this, it is important to improve not only the quality of manufacture and activation, but also the selection of patients according to their dental condition, their tissue receptivity and their psychology. Simple at first glance, these therapies are actually more complex to use than they appear.

\section{References}

1. Tilkian A, Dement WC (1976) The sleep apnea syndromes. Annu Rev Med 27: 465-484.

2. Amoric M (1989) The thermoformed propellant with connecting rod of Herbst. Rev Orthop Dento Faciale 23: 493-501.

3. Martınez-Gomis J, Willaert E, Nogues L, Maribel Pascual M, Somoza M, et al. (2010) Five years of sleep apnea treatment with a mandibular advancement device. Angle Orthodontist 80.

4. Verin E, Petelle B, Raux M, Vincent G, Fleury B, et al. (2007) Effects of mandibular advancement on upper airway dynamics in awake normal subjects: A pilot study with phrenic nerve stimulation. Sleep Med 7: 368-373.

5. Lowe AA, Sjoholm TT, Ryan CF, Fleetham JA, Ferguson KA, et al. (2000) Treatment, airway and compliance effects of a titratable oral appliance. Sleep 23: S172-178.

6. Johal A (2006) Health-related quality of life in patients with sleepdisordered breathing: Effect of mandibular advancement appliances. J Prosthet Dent 96: 298-302.

7. Soll BA, George PT (1985) Treatment of obstructive sleep apnea with a nocturnal airway-patency appliance. N Engl J Med 313: 386-387.

8. Ahrens A, McGrath C, Hägg U (2011) A systematic review of the efficacy of oral appliance design in the management of obstructive sleep apnoea. Eur J Orthod 33: 318-324.

9. Lim J, Lasserson TJ, Fleetham J, Wright J (2004) Oral appliances for obstructive sleep apnoea. Cochrane Database Syst Rev: CD004435.

10. Hoffstein V (2007) Review of oral appliances for treatment of sleepdisordered breathing. Sleep Breath 11: 1-22.
11. Ahrens A, McGrath C, Hägg U (2010) Subjective efficacy of oral appliance design features in the management of obstructive sleep apnea: A systematic review. Am J Orthod Dentofacial Orthop 138: 559-576.

12. Itzhaki S, Dorchin H, Clark G, Lavie L, Lavie P, et al. (2007) The effects of 1-year treatment with a herbst mandibular advancement splint on obstructive sleep apnea, oxidative stress, and endothelial function. Chest 131: 740-749.

13. Johal A, Battagel JM (1999) An investigation into the changes in airway dimension and the efficacy of mandibular advancement appliances in subjects with obstructive sleep apnoea. Br J Orthod 26: 205-210.

14. Iwasaki T, Sato H, Suga H, Minami A, Yamamoto Y, et al. (2017) Herbst appliance effects on pharyngeal airway ventilation evaluated using computational fluid dynamics. Angle Orthod 87: 397-403.

15. Marklund M, Sahlin C, Stenlund H, Persson M, Franklin KA (2001) Mandibular advancement device in patients with obstructive sleep apnea : Long-term effects on apnea and sleep. Chest 120: 162-169.

16. Petit FX, Pépin JL, Bettega G, Sadek H, Raphaël B, et al. (2002) Respiratory disturbance index an independent predisctor of mortality in coronary artery diseases. Am J Respir Crit Care Med 162: 274-278.

17. Robertson C, Herbison P, Harkness M (2003) Dental and occlusal changes during mandibular advancement splint therapy in sleep disordered patients, Eur J Orthod 25: 371-376.

18. Ringqvist M, Walker-Engstrom ML, Tegelberg A, Ringqvist I (2003) Dental and skeletal changes after 4 years of obstructive sleep apnea treatment with a mandibular advancement device: A prospective, randomized study. Am J Orthod Dentofacial Orthop 124: 53-60.

19. Fransson AM, Tegelberg A, Johansson A, Wenneberg B (2004) Influence on the masticatory system in treatment of obstructive sleep apnea and snoring with a mandibular protruding device: A 2-year follow-up. Am J Orthod Dentofacial Orthop 126: 687-693.

20. Almeida FR, Lowe AA, Sung JO, Tsuiki S, Otsuka R (2006) Long-term sequellae of oral appliance therapy in obstructive sleep apnea patients: Part 1. Cephalometric analysis. Am J Orthod Dentofacial Orthop 129: 195-204.

21. Doff MH, Hoekema A, Pruim GJ, Huddleston Slater JJ, Stegenga B (2010) Long-term oral-appliance therapy in obstructive sleep apnea: A cephalometric study of craniofacial changes. J Dent 38: 1010-1018.

22. Clark GT, Sohn JW, Hong CN (2000) Treating obstructive sleep apnea and snoring: Assessment of an anterior mandibular positioning device. J Am Dent Assoc 131: 765-771.

23. Battagel JM, Kotecha B (2005) Dental side-effects of mandibular advancement splint wear in patients who snore. Clin Otolaryngol 30: 149-155

24. Hugentobler M, Scolozzi P (2010) Severe dental malocclusion: A rare and insidious complication of mandibular advancement devices for obstructive sleep apnea syndrome treatment. Oral Surg Oral Med Oral Pathol Oral Radiol Endod 109: e28-32.

25. Durán J, Esnaola S, Rubio R, Iztueta A (2001) Obstructive sleep apneahypopnea and related clinical features in a population-based sample of subjects aged 30 to 70 yr. Am J Respir Crit Care Med 163: 685-689. 